University of South Florida

DIGITAL COMMONS

Digital Commons @ University of

@ UNIVERSITY OF SOUTH FLORIDA

South Florida

Marine Science Faculty Publications

College of Marine Science

$11-30-2010$

\title{
Ocean Mass from GRACE and Glacial Isostatic Adjustment
}

D. Chambers

University of South Florida, donc@usf.edu

John Wahr

University of Colorado

Mark E. Tamisea

National Oceanographic Centre

R Steven Nerem

University of Colorado

Follow this and additional works at: https://digitalcommons.usf.edu/msc_facpub

Part of the Marine Biology Commons

\section{Scholar Commons Citation}

Chambers, D.; Wahr, John; Tamisea, Mark E.; and Nerem, R Steven, "Ocean Mass from GRACE and Glacial Isostatic Adjustment" (2010). Marine Science Faculty Publications. 175.

https://digitalcommons.usf.edu/msc_facpub/175

This Article is brought to you for free and open access by the College of Marine Science at Digital Commons @ University of South Florida. It has been accepted for inclusion in Marine Science Faculty Publications by an authorized administrator of Digital Commons @ University of South Florida. For more information, please contact digitalcommons@usf.edu. 


\title{
Ocean mass from GRACE and glacial isostatic adjustment
}

\author{
Don P. Chambers, ${ }^{1}$ John Wahr, ${ }^{2,3}$ Mark E. Tamisiea, ${ }^{4}$ and R. Steven Nerem ${ }^{3,5}$ \\ Received 5 March 2010; revised 28 June 2010; accepted 20 August 2010; published 30 November 2010.
}

[1] We examine geoid rates and ocean mass corrections from two published global glacial isostatic adjustment (GIA) models, both of which have been used in previous studies to estimate ocean mass trends from Gravity Recovery and Climate Experiment (GRACE) satellite gravity data. These two models are different implementations of the same ice loading history and use similar mantle viscosity profiles. The model results are compared with each other and with geoid rates determined from GRACE during August 2002 to November 2009. When averaged over the global ocean, the two models have rates that differ by nearly $1 \mathrm{~mm} \mathrm{yr}^{-1}$ of ocean mass, with the first model giving a correction closer to $2 \mathrm{~mm} \mathrm{yr}^{-1}$ and the second closer to $1 \mathrm{~mm} \mathrm{yr}^{-1}$. By comparing the two models, we have discovered that $50 \%$ of the difference is caused by a global (land + ocean) mean in the first model. While it is appropriate to include this mean when subtracting GIA effects from measurements of sea level change measured by tide gauges or satellite altimetry, the mean should not be included when subtracting GIA effects from ocean mass variations derived from satellite gravity data. When this mean is removed, the ocean mass corrections from the two models still disagree by $0.4 \mathrm{~mm} \mathrm{yr}^{-1}$. We trace the residual difference to the fact that the first model also has large trends over the ocean related to large rates in its predicted degree 2, order 1 geoid coefficients. Such oceanic trends are not observed by GRACE nor are they predicted by the second model, and they are shown to be inconsistent with the polar wander rates predicted by the first model itself. If these two problems are corrected, we find that the two model predictions agree at the 3\% level. On the basis of this analysis, we conclude that the ocean mass correction for GRACE is closer to $1 \mathrm{~mm} \mathrm{yr}^{-1}$ than $2 \mathrm{~mm} \mathrm{yr}^{-1}$, although significant uncertainties remain.

Citation: Chambers, D. P., J. Wahr, M. E. Tamisiea, and R. S. Nerem (2010), Ocean mass from GRACE and glacial isostatic adjustment, J. Geophys. Res., 115, B11415, doi:10.1029/2010JB007530.

\section{Introduction}

[2] Several investigations have used the multiyear record of GRACE data to examine trends in ocean mass related to climate change [Lombard et al., 2007; Willis et al., 2008; Leuliette and Miller, 2009; Cazenave et al., 2009]. The primary factor leading to significant differences in trend estimates is the choice of glacial isostatic adjustment (GIA) model used in the processing, as the correction is the same order as the expected mass trend (approximately 1 to $2 \mathrm{~mm}$ $\mathrm{yr}^{-1}$ of equivalent sea level rise). GRACE measures all gravity variations, including those caused by ongoing GIA. To determine the ocean mass trends related to modern exchanges of water mass between the oceans and continents,

\footnotetext{
${ }^{1}$ College of Marine Science, University of South Florida, St. Petersburg, Florida, USA.

${ }^{2}$ Department of Physics, University of Colorado at Boulder, Boulder, Colorado, USA.

${ }^{3}$ CIRES, University of Colorado at Boulder, Boulder, Colorado, USA.

${ }^{4}$ National Oceanographic Centre, Liverpool, UK.

${ }^{5}$ Colorado Center for Astrodynamics Research, University of Colorado at Boulder, Boulder, Colorado, USA.

Copyright 2010 by the American Geophysical Union. 0148-0227/10/2010JB007530
}

one must remove the gravitational effect of the solid Earth's and ocean's adjustment to the large-scale deglaciation following the Last Glacial Maximum.

[3] The only straightforward way to do this is to use a GIA model. Otherwise, one needs to perform complex inversions of multiple data sets (e.g., GRACE, GPS, ocean bottom pressure) and such inversions are still quite uncertain in terms of trends because of reference frame drift [e.g, $W u$ et al., 2006]. The differences between most GIA models arise from three main causes: the solid Earth model used, particularly the viscosity profile and lithospheric thickness; the ice loading history (most publicly available global models currently use the ICE-5G history [Peltier, 2004]); and the treatment of polar wander. Peltier [2009] and Peltier and Luthcke [2009] recently addressed the latter issue and concluded that the Peltier [2004] GIA model is the most appropriate one to use for GRACE ocean mass computations. It yields a significantly larger correction (quoted by Peltier [2009] as $1.80 \mathrm{~mm} \mathrm{yr}^{-1}$ of sea level rise) than other models [e.g., Paulson et al., 2007]. Although many other GIA models do exist, either they tend to be more regional [e.g., Milne et al., 2001; Ivins and Wolf, 2008] or they give corrections that are similar to the Paulson et al. value [e.g., Mitrovica et al., 2005]. The Paulson and Peltier models 
represent the largest deviation of global GIA models that have been used in the literature of ocean mass change from GRACE [Willis et al., 2008; Leuliette and Miller, 2009; Cazenave et al., 2009], and it is important to understand the differences, especially since they are both based on the same ice loading history (ICE-5G) [Peltier, 2004], as well as similar viscosity profiles. In this investigation, we will examine the differences between the Paulson et al. [2007] (from here on, referred to simply as Paulson et al.) and Peltier [2004] (similarly, referred to as Peltier) models in order to understand whether the differences reflect an error in one or both of the models or rather represent an inherent uncertainty in the GIA correction. An uncertainty of order $1 \mathrm{~mm} \mathrm{yr}^{-1}$ in GIA models would significantly limit the usefulness of GRACE measurements for measuring ocean mass trends.

[4] Although Peltier [2009] and Peltier and Luthcke [2009] proposed that the differences were related to the rotational feedback theory that Paulson et al. use, from Mitrovica et al. [2005], we find that the effect of rotational feedback is too small to explain those differences. Instead, we will demonstrate that the differences can be explained by a global (land + ocean) bias in the Peltier model that is inconsistent with use for GRACE observations, as well as rates in Peltier's degree 2, order 1 coefficients that are inconsistent (i.e., 5-6 times too large) with the polar motion values predicted by the same Peltier model.

[5] In section 2, we describe the two models and the GRACE data we use for comparison and will discuss any special processing done to the data. In the remaining sections, we will discuss the initial comparisons of the models in terms of the ocean mass correction and the patterns of implied geoid rates, then discuss the polar motion feedback terms, and finally propose why we believe the two models diverge so significantly.

\section{GIA Model Descriptions and Special Data Processing}

[6] Peltier's [2004] geoid rates for the ICE-5G(VM2) model are provided as $1^{\circ}$ gridded values with units of $\mathrm{mm}$ $\mathrm{yr}^{-1}$. In order to use these rates in the same way that we process GRACE spherical harmonic coefficients distributed by the GRACE project, the GIA geoid map is decomposed into Stokes (i.e., spherical harmonic) gravity coefficients with the same spherical harmonic normalization and Earth radius value utilized by the GRACE project [Bettadpur, 2007]. The map is decomposed into coefficients from degree and order 0 to 180 . We include the degree and order 0 term $\left(\mathrm{C}_{0,0}\right)$ to estimate any mean in the grid. For gravity, $\mathrm{C}_{0,0}$ is proportional to the total mass of the Earth and all its components and should not change over time, either in the GIA model output or in the GRACE data. For the GRACE project, this constraint is enforced in the processing by requiring that monthly estimates of the change in $\mathrm{C}_{0,0}$ $\left(\Delta \mathrm{C}_{0,0}\right)$ are identically zero. However, the gridded ICE-5G (VM2) geoid rate map of Peltier has a significant nonzero global (land + ocean) average of $-0.21 \mathrm{~mm} \mathrm{yr}^{-1}$. This nonzero mean should not be included when correcting GRACE data. The true GIA correction to the change in the Earth's gravitational potential must have a global average that is identically zero, since otherwise the GIA model would not conserve the Earth's total mass.

[7] A nonzero mean is, however, required when removing GIA effects from altimeter or tide gauge observations of sea level change. The correction in that case should equal the gravitational potential plus a spatially uniform term needed to conserve ocean mass. Suppose, for example, GIA caused a net seafloor subsidence when averaged over the entire ocean but caused no average change in the gravitational potential. The globally averaged sea surface height in this case would have to fall, since otherwise the ocean would gain mass. Thus, a global constant would have to be subtracted from the gravitational potential when constructing the GIA altimeter correction, but not for the GRACE correction. We suspect that the errant $-0.21 \mathrm{~mm} \mathrm{yr}^{-1}$ global mean in Peltier's [2004] model is a remnant of when those corrections were used to correct altimeter data. Whatever the origin, it must be removed before applying the correction to GRACE data. This mean has an important effect on the results discussed by Peltier [2009] and Peltier and Luthcke [2009], leading to a reduction in the estimated ocean mass correction of $0.4 \mathrm{~mm} \mathrm{yr}^{-1}$ (Table 1). This is discussed in more detail in section 3 .

[8] The second model we examine is from Paulson et al. [2007]. It uses the ICE-5G ice load model and a two-layer approximation of the VM2 mantle viscosity profile from Peltier [2004]. It uses a significantly different theory for the rotational feedback caused by polar wander [Mitrovica et al., 2005], which affects mainly the degree 2, order 1 coefficients, as discussed by Peltier [2009]. This model has no global mean bias. We will discuss the differences resulting from these two GIA models in more detail in section 3. The model of Paulson et al. [2007] is also decomposed into Stokes coefficients using the GRACE spherical harmonic normalization and Earth radius value, although only to degree and order 70 . The difference in the computed ocean mass correction for an expansion to degree and order 120 versus degree/order 70 is $0.01 \mathrm{~mm} \mathrm{yr}^{-1}$ (Table 1).

[9] For the GRACE data, we utilize the Center for Space Research Release-04 data [Bettadpur, 2007], where the degree 2 , order 0 coefficients are replaced with estimates based on satellite laser ranging tracking to geodetic satellites [Cheng and Tapley, 2004]. The coefficients are not filtered to remove correlated errors that cause vertical stripes in the maps [e.g., Swenson and Wahr, 2006], because the stripes have significantly smaller wavelengths than the spatial scales we are considering (Gaussian smoothing radii $>600 \mathrm{~km}$ ). The ocean dealiasing model used in the processing is not restored, as typically done when studying local variations in ocean mass [e.g., Chambers, 2006], so that the only oceanographic signals remaining in the GRACE data are those due to errors and omissions in the model. We also remove the gravitational signal from the soil moisture and snow mass parameters output from the Global Land Data Assimilation System (GLDAS) based on the Noah land surface model [Rodell et al., 2004]. Model output over Greenland is not used because of problems with erroneous accumulation of snow, and there is no model output for Antarctica. GLDAS is removed to reduce some of the variability related to hydrology, but one should note that the model does not output surface water changes, snow in many areas, or 
Table 1. Rate of GIA Over the Ocean in Equivalent Sea Level (in $\mathrm{mm} \mathrm{yr}^{-1}$ )

\begin{tabular}{|c|c|}
\hline Model, Truncation, Coefficients Used, Ocean Kernel & Mass Rate (mm of SL $\mathrm{yr}^{-1}$ ) \\
\hline $\begin{array}{l}\text { Peltier [2004], to degree } 120 \text {, all coefficients including } \mathrm{C}_{0,0} \text {, ocean kernel including Hudson } \\
\text { Bay and West Antarctic Ice Shelf }\end{array}$ & -1.81 \\
\hline $\begin{array}{l}\text { Peltier [2004], to degree } 60 \text {, all coefficients including } \mathrm{C}_{0,0} \text {, ocean kernel including Hudson } \\
\text { Bay and West Antarctic Ice Shelf }\end{array}$ & -1.80 \\
\hline $\begin{array}{l}\text { Peltier [2004], to degree } 60 \text {, all coefficients including } \mathrm{C}_{0,0} \text {, ocean kernel excluding Hudson } \\
\text { Bay and West Antarctic Ice Shelf }\end{array}$ & -1.91 \\
\hline $\begin{array}{l}\text { Peltier [2004], to degree } 60 \text {, all coefficients including } \mathrm{C}_{0,0} \text {, ocean kernel masking oceans } \\
\text { within } 300 \mathrm{~km} \text { of continents }\end{array}$ & -2.00 \\
\hline $\begin{array}{l}\text { Peltier [2004], to degree } 60 \text {, all coefficients degree } 1 \text { and higher, ocean kernel masking } \\
\text { oceans within } 300 \mathrm{~km} \text { of continents }\end{array}$ & -1.61 \\
\hline $\begin{array}{l}\text { Peltier [2004], to degree } 60 \text {, all coefficients degree } 2 \text { and higher, ocean kernel masking } \\
\text { oceans within } 300 \mathrm{~km} \text { of continents }\end{array}$ & -1.59 \\
\hline $\begin{array}{l}\text { Peltier [2004], to degree } 60 \text {, all coefficients degree } 2 \text { and higher except degree } 2 \text {, order } 1 \text {, } \\
\text { ocean kernel masking oceans within } 300 \mathrm{~km} \text { of continents }\end{array}$ & -1.16 \\
\hline $\begin{array}{l}\text { Peltier [2004], to degree } 60 \text {, all coefficients degree } 2 \text { and higher with degree } 2 \text { order } \\
1 \text { replaced with values from (9), ocean kernel masking oceans within } 300 \mathrm{~km} \text { of continents }\end{array}$ & -1.22 \\
\hline $\begin{array}{l}\text { Peltier [2004], to degree } 60 \text {, all coefficients degree } 2 \text {, order } 2 \text { and higher, ocean kernel } \\
\text { masking oceans within } 300 \mathrm{~km} \text { of continents }\end{array}$ & -1.02 \\
\hline $\begin{array}{l}\text { Paulson et al. [2007], to degree } 60 \text {, coefficients degree } 2 \text { and higher, ocean kernel } \\
\text { excluding Hudson Bay and West Antarctic Ice Shelf }\end{array}$ & -1.14 \\
\hline $\begin{array}{l}\text { Paulson et al. [2007], to degree } 60 \text {, coefficients degree } 2 \text { and higher, ocean kernel } \\
\text { masking oceans within } 300 \mathrm{~km} \text { of continents }\end{array}$ & -1.27 \\
\hline $\begin{array}{l}\text { Paulson et al. [2007], to degree } 60 \text {, all coefficients degree } 2 \text { and higher except degree } 2 \text {, } \\
\text { order } 1 \text {, ocean kernel masking oceans within } 300 \mathrm{~km} \text { of continents }\end{array}$ & -1.24 \\
\hline $\begin{array}{l}\text { Paulson et al. [2007], to degree } 60 \text {, all coefficients degree 2, order } 2 \text { and higher, ocean } \\
\text { kernel masking oceans within } 300 \mathrm{~km} \text { of continents }\end{array}$ & -1.10 \\
\hline
\end{tabular}

${ }^{a}$ Different models, spherical harmonic expansion, coefficients, and ocean kernels were used. No additional smoothing was done to the data other than truncation, which is consistent with the method we use to compute ocean mass from GRACE.

groundwater. A linear trend in the GRACE residuals is estimated in each coefficient for degrees 2 and higher using more than 7 years of monthly coefficients from August 2002 until November 2009. The linear trend is estimated simultaneously with a constant, annual and semiannual sinusoids, and a sinusoid for the S2 tidal alias period (161 days). The trend is mapped into a grid of geoid rates, which are compared in section 3 to equivalent maps showing GRACE results after one or the other of the two GIA models has been removed and after smoothing with a Gaussian radius of 600 $\mathrm{km}$.

\section{Initial Comparisons of Ocean Mass Corrections and Geoid Rates}

[10] Peltier [2009] estimates that the GIA correction to GRACE global ocean mass estimates from ICE-5G(VM2) is $-1.80 \mathrm{~mm} \mathrm{yr}^{-1}$ in equivalent sea level. We use the Stokes coefficients computed from Peltier's geoid rates in an attempt to reproduce this value. We use three different ocean kernels and several different levels of spherical harmonic truncation and compute results for both Peltier's and Paulson et al.'s geoid rates (Table 1). The results do not vary by more than $0.01 \mathrm{~mm} \mathrm{yr}^{-1}$ when we change from an expansion to degree/ order 60 to one to degree/order 120 . Thus, the majority of the signal in the GIA ocean mass correction occurs at degrees lower than 60, which is compatible with the truncation of the CSR GRACE data. However, the values do change by up to $0.2 \mathrm{~mm} \mathrm{yr}^{-1}$ depending on the ocean kernel used. We can reproduce Peltier's [2009] $-1.80 \mathrm{~mm} \mathrm{yr}^{-1}$ value only if we include Hudson Bay and the ocean under the West Antarctic ice shelves (Table 1). However, these areas are generally excluded from computing ocean mass from GRACE because of the problem of leakage from hydrology and modern day ice loss [Chambers, 2009]. Instead, a kernel that excludes ocean within $300 \mathrm{~km}$ of continents is preferred, with no additional smoothing other than the truncation of the gravity coefficients [Chambers, 2009]. Using this kernel increases the correction derived from Peltier's model, to $-2.00 \mathrm{~mm} \mathrm{yr}^{-1}$ (Table 1), likely because this kernel masks out the large positive GIA rates over Hudson Bay. For the remainder of the discussion, we will compare results using this masked ocean kernel and truncating to degree/order 60 .

[11] We also find the only way we can use Peltier's geoid rates to obtain an ocean mass correction value as large as the one proposed by Peltier [2009] is if we include the mean in the model $\left(\Delta \mathrm{C}_{0,0}\right)$. When we remove the mean and recompute the ocean mass average with the preferred ocean kernel, the correction drops to $-1.61 \mathrm{~mm} \mathrm{yr}^{-1}$ of equivalent sea level, a decrease of about $50 \%$ of the mean difference between the Peltier and Paulson et al. values $\left(-2.00 \mathrm{~mm} \mathrm{yr}^{-1}\right.$ for Peltier, $-1.27 \mathrm{~mm} \mathrm{yr}^{-1}$ for Paulson et al.; see Table 1). As discussed in section 2, the GIA correction to GRACE should not include that mean.

[12] One other small difference between the Peltier model and the GRACE data is that the GRACE coefficients are given in the center-of-mass frame and so do not include degree 1 terms. Peltier's geoid rates are computed in a different frame and do include degree 1 terms, which then contribute to his GIA GRACE correction. This has the possibility of causing additional differences between the two GRACE corrections, since the Paulson et al. model results are presented in the center-of-mass frame. This discrepancy, however, is unimportant, because the degree 1 terms of Peltier's GIA model account for only $0.02 \mathrm{~mm} \mathrm{yr}^{-1}$ of the correction (Table 1).

[13] If we remove the mean and degree 1 terms from the Peltier model, the ocean mass corrections implied by the two 
a)

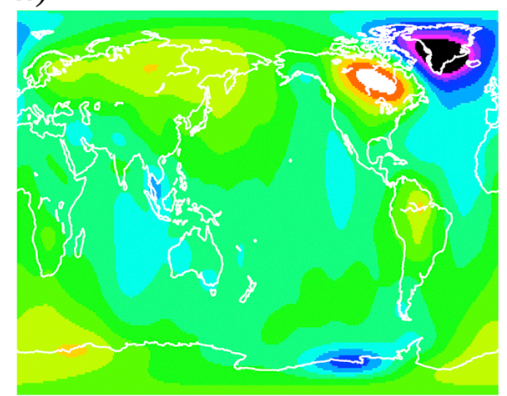

c)

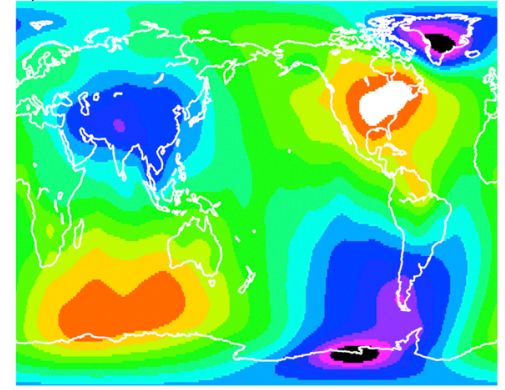

e)

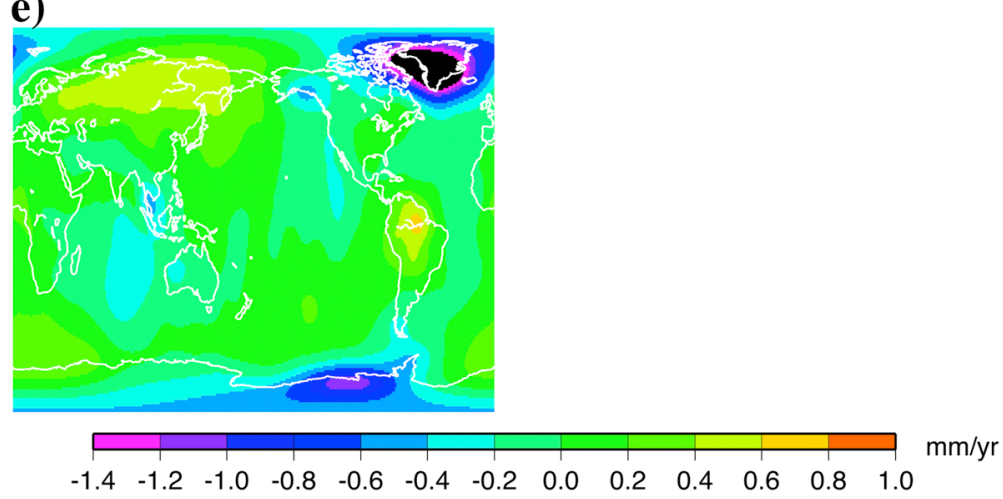

b)

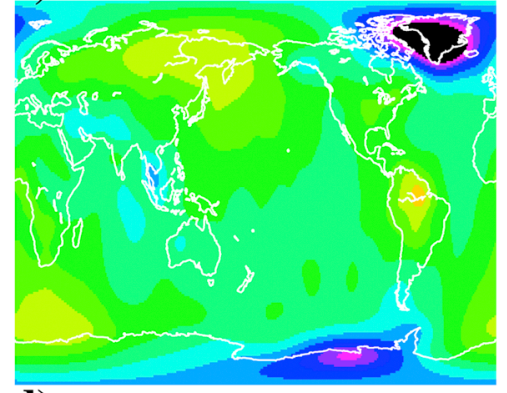

d)

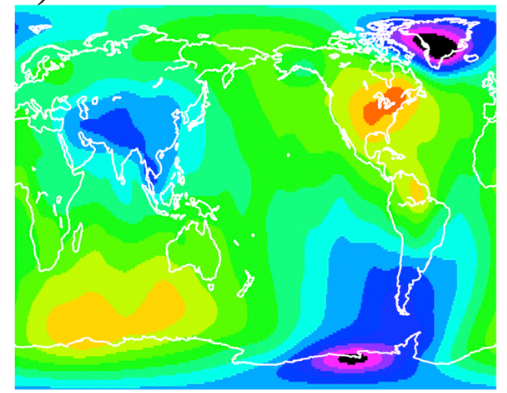
$\mathrm{mm} / \mathrm{yr}$

Figure 1. Secular trends in geoid from August 2002 until November 2009 observed by (a) GRACE, (b) GRACE corrected for the Paulson et al. GIA model, and (c) GRACE corrected for the Peltier GIA model. (d) Same as Figure 1c, but degree 2, order 1 terms in Figure 1c have been scaled to remove the effects of polar wander feedback. (e) Same as Figure 1c, but degree 2, order 1 values have been replaced with values that are consistent with the polar wander rates of Peltier and Luthcke [2009]. For details of calculations, see text.

GIA models agree to about $30 \%\left(-1.59 \mathrm{~mm} \mathrm{yr}^{-1}\right.$ for Peltier and $-1.27 \mathrm{~mm} \mathrm{yr}^{-1}$ for Paulson et al). This difference is almost entirely due to different secular rates for the degree 2, order 1 Stokes coefficients $\left(\dot{C}_{21}, \dot{S}_{21}\right)$ predicted by the two models. If those terms (and the global mean and degree 1 terms in Peltier's model) are excluded, the ocean mass corrections become $-1.16 \mathrm{~mm} \mathrm{yr}^{-1}$ for Peltier and $-1.24 \mathrm{~mm} \mathrm{yr}^{-1}$ for Paulson et al., a difference of only $4 \%$. Note that removing the $\left(\dot{C}_{21}, \dot{S}_{21}\right)$ contributions reduces the Peltier correction by $27 \%$, but only reduces the Paulson et al. correction by about $2 \%$. The reason is that those terms constitute a much larger fraction of the total geoid rate in Peltier's model than in Paulson et al.'s model (Figure 1).

[14] Figure 1a shows the mapped geoid rate obtained from 6 years of GRACE data, with GLDAS hydrology and the ocean dealiasing model removed. Figures $1 \mathrm{~b}$ and $1 \mathrm{c}$ show the same GRACE results but after removing the Paulson et al. and Peltier models, respectively. Clearly, the Paulson et al. model predicted geoid rates are closer to the rates observed by GRACE (after removing modeled ocean and hydrology trends). In fact, Figure 1c shows that the removal of Peltier's model introduces large secular geoid trends over central Asia, the eastern United States, and the southern ocean, which are not present in the uncorrected GRACE results. It is the average of those features over the global ocean that is responsible for most of the $30 \%$ difference between the Paulson et al. and Peltier ocean mass values (after the mean and degree 1 terms have been removed from Peltier's model).

[15] The four anomalous features visible in Figure 1c come from the large $\left(\dot{C}_{21}, \dot{S}_{21}\right)$ coefficients in Peltier's model. If Peltier's values for these coefficients are correct, some non-GIA mechanism(s) would have to be producing those four features. This issue was discussed in general terms by Peltier and Luthcke [2009], who suggested that perhaps present-day changes in land ice have been producing $\left(\dot{C}_{21}, \dot{S}_{21}\right)$ values that offset Peltier's GIA cor- 
rections. They argued that a trend in land ice would cause a trend in the Earth's inertia tensor, thus leading to a drift in the pole position. That polar drift would cause degree 2 , order 1 deformation and so would produce $\left(\dot{C}_{21}, \dot{S}_{21}\right)$ terms. We show in section 4 , however, that for ongoing mass loss the $\left(\dot{C}_{21}, \dot{S}_{21}\right)$ values caused by polar motion would be only about $30 \%$ of the total $\left(\dot{C}_{21}, S_{21}\right)$ values, so that when the results in Figure 1c are corrected for this polar motion feedback contribution (i.e., Figure 1d), the four lobes still remain.

[16] One should note, incidentally, that when Peltier [2009] and Peltier and Luthcke [2009] compared maps of ICE-5G (VM2) with GRACE, only coefficients degree 2, order 2 and above were used. Thus, the portion of the GIA model that differed most from the GRACE observations was excluded from their comparisons. When the degree 2, order 1 terms are included (as is required when computing the complete ocean mass correction), the large trends shown in Figure 1c are obtained.

\section{Polar Motion Feedback From Contemporary Mass Loads}

[17] The total geoid contribution from land-based ice (or from any other mass load) can be written as [e.g., Wahr et al., 1998],

$$
\begin{aligned}
N= & a \sum_{l, m} P_{l m}(\cos \theta)\left[C_{l m}^{\mathrm{L}} \cos m \phi+S_{l m}^{\mathrm{L}} \sin m \phi\right] \\
& +a P_{21}(\cos \theta)\left[C_{21}^{\mathrm{ROT}} \cos \phi+S_{21}^{\mathrm{ROT}} \sin \phi\right]
\end{aligned}
$$

where $\theta$ and $\phi$ are colatitude and eastward longitude, $a$ is the Earth's radius, and the $P_{l m}(\cos \theta)$ is the associated Legendre function. Here we have separated the Stokes coefficients into contributions $\left(C_{l m}^{\mathrm{L}}, S_{l m}^{\mathrm{L}}\right)$ caused by the direct gravitational attraction of the mass load and the Earth's deformation beneath the load and contributions $\left(C_{21}^{\mathrm{ROT}}, S_{21}^{\mathrm{ROT}}\right)$ caused by polar motion feedback. Although this feedback causes small perturbations to all harmonics because of coupling through the sea level equation, its dominant contribution by far is to the degree 2 , order 1 coefficients. So for simplicity, those are the only ROT coefficients we will consider.

[18] Define the complex variables $\bar{c}(t)=C_{21}(t)+i S_{21}(t)$, $\bar{I}(t)=I_{x z}(t)+i I_{y z}(t)$, and $\bar{m}(t)=m_{x}(t)+i m_{y}(t)$ to represent the degree 2 , order 1 Stokes coefficients, the products of inertia, and the pole position, respectively $\left(m_{x}\right.$ and $m_{y}$ are the components of the rotation axis in the mean equatorial plane). The total contribution to the degree 2, order 1 Stokes coefficients will be represented without a superscript, so that $\bar{c}(t)=\bar{c}^{\mathrm{L}}(t)+\bar{c}^{\mathrm{ROT}}(t)$. We use this same superscript convention for $\bar{I}(t)$ and $\bar{m}(t)$. The degree 2 order 1 Stokes coefficients are proportional to the products of inertia [see Chao and Gross, 1987, equation (12)]:

$$
\begin{aligned}
\bar{c}^{\mathrm{L}}(t) & =-\sqrt{\frac{3}{5} \frac{1}{M a^{2}}} \bar{I}^{\mathrm{L}}(t) \\
\bar{c}^{\mathrm{ROT}}(t) & =-\sqrt{\frac{3}{5}} \frac{1}{M a^{2}} \bar{I}^{\mathrm{ROT}}(t) \\
\bar{c}(t) & =-\sqrt{\frac{3}{5}} \frac{1}{M a^{2}} \bar{I}(t),
\end{aligned}
$$

where $M$ and $a$ are the Earth's mass and mean radius. So the relative amplitude of $\dot{\bar{c}}^{\mathrm{ROT}}$ to $\dot{\bar{c}}(t)$ is the same as the relative amplitude of $\dot{\bar{I}}^{\mathrm{ROT}}$ to $\dot{\bar{I}}$.

[19] The products of inertia caused by the polar motioninduced deformation of the Earth are [see Munk and MacDonald, 1975, equations 6.1.8]

$$
\bar{I}^{\mathrm{ROT}}(t)=(C-A) \frac{k^{\mathrm{T}}}{k_{f}} \bar{m}(t),
$$

where $k^{\mathrm{T}}$ is the degree 2 body tide Love number and $k_{f}$ is the fluid Love number. Multiyear trends in polar motion and in the total product of inertia are related by (see Appendix A)

$$
\dot{\bar{m}}(t)=\frac{1}{C-A} \dot{\bar{I}}(t)
$$

(where we reiterate that $\dot{\bar{I}}$ includes all contributions to the products of inertia: those from the mass load, from the deformation of the Earth caused by that mass load, and from the deformation cased by polar motion feedback). Taking the time derivative of (2) and combining with (3) gives

$$
\dot{\bar{I}}^{\mathrm{ROT}}=\frac{k^{\mathrm{T}}}{k_{\mathrm{f}}} \dot{\bar{I}} .
$$

Since $k^{\mathrm{T}}=0.30$ [e.g., Smith and Dahlen, 1981, Table 3] and $k_{\mathrm{f}}=0.94$ [e.g., Peltier and Luthcke, 2009, equation (12)], $\dot{\bar{I}}^{\text {ROT }}=0.32 \dot{\bar{I}}$. So because of (1),

$$
\dot{\bar{c}}^{\text {ROT }}=0.32 \dot{\bar{c}}
$$

implying that the rotational feedback contributions to the $\left(\dot{C}_{21}, \dot{S}_{21}\right)$ coefficients are only $32 \%$ of the total. So the direct contribution to $\left(\dot{C}_{21}, \dot{S}_{21}\right)$ from the ice and underlying solid Earth elastic deformation will be $68 \%$ of the total value. The presence of an equilibrium ocean would increase the effective value of $k^{\mathrm{T}}$ by about $12 \%$, over the value used here [see Agnew and Farrell, 1978]. That would increase the relative importance of the rotational contributions to about $36 \%$, which is a small enough modification to have no significant impact on the discussion below.

[20] Suppose that Peltier's [2004] model for the GIA geoid rate is correct and that the difference between GRACE and Peltier's model shown in Figure 1c is, as suggested by Peltier and Luthcke, caused by contemporary changes in ice mass. Equation (5) shows that the effects of polar potion feedback can be removed from Figure 1c by multiplying the $\left(\dot{C}_{21}, \dot{S}_{21}\right)$ coefficients in the GRACE-minusPeltier residuals by $1-0.32=0.68$. We use these rescaled $\left(\dot{C}_{21}, \dot{S}_{21}\right)$ coefficients, along with all the other Stokes coefficients, and recompute the GRACE-minus-Peltier results in the latitude/longitude domain. The result is shown in Figure 1d. This map would then represent the direct effects of the contemporary ice change plus the underlying load-induced solid Earth deformation (the latter contributes a geoid signal that is typically about $5 \%-10 \%$ of the direct effects of the surface mass load and has a similar spatial pattern). The pattern of the residuals shown in Figure 1d should now closely mirror the pattern of the surface mass load. The map, however, is still dominated by the same four lobes (over southcentral Asia, the northeastern United 


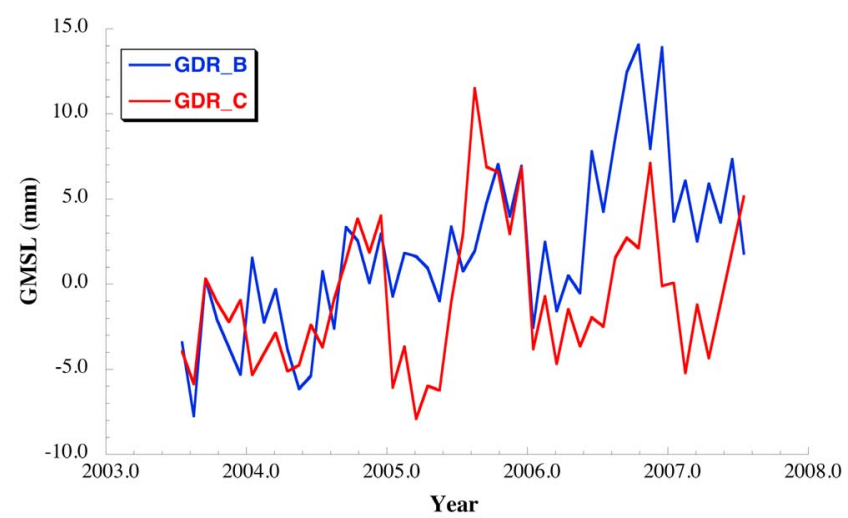

Figure 2. GMSL computed from Jason-1 for older GDR-B version of data (blue) and newer GDR-C version of data (red).

States, and the southern ocean) evident in Figure 1c. That is because the $\left(\dot{C}_{21}, \dot{S}_{21}\right)$ residuals are still anomalously large, even after removing the polar motion contributions.

[21] This pattern does not look like what one would expect from a contemporary change in land ice. Nor does it look like any other surface mass trend we are aware of. Over the southern ocean, for example, the residuals shown in Figure $1 \mathrm{~d}$ are on the order of $\pm 1 \mathrm{~mm} \mathrm{yr}^{-1}$ of geoid in places. These variations are larger than any comparable fluctuation in the ocean that has been modeled or observed. For instance, the largest residual ocean trend in the GRACE data before applying a GIA correction is in the North Pacific and has a magnitude of order $0.5 \mathrm{~mm} \mathrm{yr}^{-1}$ (in terms of geoid rate). That feature has been validated as a real trend in ocean bottom pressure [Chambers and Willis, 2008]. Subtracting the Paulson et al. [2007] model, on the other hand, does not significantly increase any regional ocean geoid variations.

[22] Another argument, made by Peltier [2009] and Peltier and Luthcke [2009] that Peltier's model (including the mean) should be used for GRACE ocean mass calculations, is based on closing the sea level budget between ocean mass from GRACE, steric sea level from Argo, and total sea level from altimetry, following the work of Willis et al. [2008], Cazenave et al. [2009], and Leuliette and Miller [2009]. Their main argument is based on comparing the results from Cazenave et al. [2009], who find closure when they use the Peltier [2009] correction, and those from Leuliette and Miller [2009], who use the Paulson et al. correction and find differences of $1 \mathrm{~mm} \mathrm{yr}^{-1}$. However, this argument ignores uncertainty in the three data sets that go into the closure. The Argo rates from Willis et al. [2008] and Leuliette and Miller [2009] differ by nearly $1 \mathrm{~mm} \mathrm{yr}^{-1}$ because of the choice of climatology used in the mapping of Argo data [Leuliette and Miller, 2009]. The difference in Argo rates between Leuliette and Miller [2009] and Cazenave et al. [2009], based on the same time interval, is $0.5 \mathrm{~mm} \mathrm{yr}^{-1}$. Using conservative uncertainty estimates that include errors beyond formal errors, such as errors in the Argo trends, errors in altimetry, and errors in GRACE, both Willis et al. [2008] and Leuliette and Miller [2009] conclude the sea level budget closure can only be certain to within about $1 \mathrm{~mm} \mathrm{yr}^{-1}$ at the $95 \%$ confidence level, which is much greater than the residual difference between the mean ocean mass corrections from GIA for the Peltier and Paulson et al. models when neither model has a mean (Table 1). Thus, the closure of the sea level budget is probably not the best tool for judging which GIA model is correct.

[23] With that said, though, we note that one significant problem has affected all recent sea level budget studies [Willis et al., 2008; Leuliette and Miller, 2009; Cazenave et al., 2009]. All were based on Jason-1 GDR-B altimeter data, which have since been replaced by a new version (GDR-C) that corrects errors related to the sea state bias model, the onboard tracking algorithm, and bias jumps in the microwave radiometer. The new data have significantly lower trends in mean sea level over the time intervals considered in the three studies, by $0.7 \mathrm{~mm} \mathrm{yr}^{-1}$ (Figure 2). The trend difference appears to be caused by a jump in the GDR-B Jason-1 data in late 2006; before this the trends in the two time series agree to better than $0.2 \mathrm{~mm} \mathrm{yr}^{-1}$. Utilizing these new Jason-1 trends, and examining the sea level budget closure argument that Peltier [2009] and Cazenave et al. [2009] have used for selecting the Peltier GIA correction, we note that the error in balancing would reduce to only $0.4 \mathrm{~mm} \mathrm{yr}^{-1}$ for Leuliette and Miller [2009] (using the Paulson et al. model) but increase to $0.8 \mathrm{~mm} \mathrm{yr}^{-1}$ for Cazenave et al. [2009] (using the correction proposed by Peltier [2009]), although these differences are still both within the $95 \%$ confidence level of the closure estimate. When we use a time series starting in 2005 that has more uniform global coverage of Argo profilers (Figure 3), we find closure at the $0.2 \mathrm{~mm} \mathrm{yr}^{-1}$ level when we use the Paulson et al. [2007] GIA model.

\section{Why Do the Two Models Disagree for $\left(\dot{C}_{21}, \dot{S}_{21}\right)$ ?}

[24] The GIA models from Peltier [2004] and Paulson et al. [2007] give almost identical values for GRACE ocean mass corrections (after removing the mean from Peltier's model), if the $\left(\dot{C}_{21}, \dot{S}_{21}\right)$ terms are not included. Given this good agreement, it is natural to wonder why the models

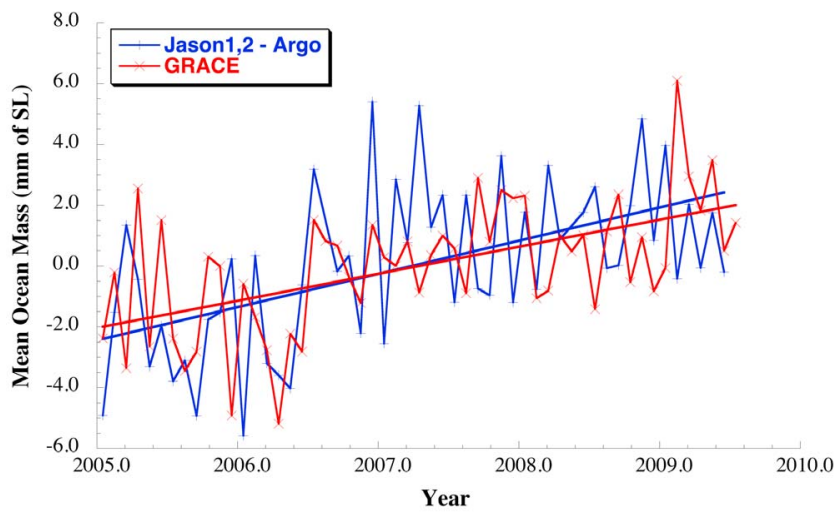

Figure 3. Nonseasonal mean ocean mass variations from GRACE (red) and Jason-1 and Jason-2 altimetry corrected for steric changes computed from Argo, computed as in the work of Willis et al. [2008]. The only change from Willis et al. [2008] is the longer time series and using GDR-C data for Jason-1 and Jason-2. The least squares linear trends are the thick solid lines. 
obtain such different results for $\left(\dot{C}_{21}, \dot{S}_{21}\right)$. These are the terms most affected by polar motion feedback, and so differences in how that feedback is modeled are important. In principle, the two models should differ primarily because Paulson et al. included the effects of small nonhydrostatic contributions to the Earth's ellipticity [see Mitrovica et al., 2005], whereas Peltier did not. These contributions have a stabilizing effect on the pole position and so can act to reduce the rotationally induced contributions to $\left(\dot{C}_{21}, \dot{S}_{21}\right)$. This, though, does not appear to be the primary reason for the difference. When Paulson et al.'s model is run without including nonhydrostatic ellipticity contributions, the resulting $\left(\dot{C}_{21}, \dot{S}_{21}\right)$ values are still many times smaller than Peltier's.

[25] In fact, there appears to be an inconsistency between the $\left(\dot{C}_{21}, \dot{S}_{21}\right)$ results in Peltier's [2004] model (values given by Peltier and Luthcke [2009]) and the polar wander rates computed for that same GIA model (values shown by Peltier and Luthcke [2009]). Combining (3) and the time derivative of the last of equations (1) gives

$$
\dot{\bar{m}}(t)=-\sqrt{\frac{5}{3}} \frac{M a^{2}}{C-A} \dot{\bar{c}}(t)
$$

which is valid for any time $t$, including the present day and where $\dot{\bar{c}}(t)$ includes all GIA contributions, i.e., from the ice and ocean loads, from the deformation of the Earth caused by those loads, and from the deformation caused by polar wander feedback. So for $t=$ the present day, $\dot{\bar{c}}(t)$ represents the total GIA-caused value of $\left(\dot{C}_{21}, \dot{S}_{21}\right)$ observed by GRACE. Using $A /(C-A) \approx 303$ and $\left(M a^{2}\right) / A \approx 1 / 0.330$ [see Groten, 2004] in (6) and separately equating the real and imaginary parts gives

$$
\left(\begin{array}{c}
\dot{m}_{x} \\
\dot{m}_{y}
\end{array}\right)=-1.2 \times 10^{3}\left(\begin{array}{c}
\dot{C}_{21} \\
\dot{S}_{21}
\end{array}\right) \text {. }
$$

Equation (34) of Peltier and Luthcke [2009] gives Peltier's [2004] values of $\left(\dot{C}_{21}, \dot{S}_{21}\right)$ as

$$
\left(\begin{array}{l}
\dot{C}_{21} \\
\dot{S}_{21}
\end{array}\right)=\left(\begin{array}{c}
-1.30 \times 10^{-11} \\
7.67 \times 10^{-11}
\end{array}\right) \quad \mathrm{yr}^{-1}
$$

From (7), this means

$$
\left(\begin{array}{c}
\dot{m}_{x} \\
\dot{m}_{y}
\end{array}\right)=\left(\begin{array}{c}
1.6 \times 10^{-8} \\
-9.2 \times 10^{-8}
\end{array}\right) \mathrm{rad} \mathrm{yr}^{-1}=\left(\begin{array}{c}
0.9 \\
-5.3
\end{array}\right) \mathrm{deg} \mathrm{Myr}^{-1} .
$$

These numbers for $\dot{m}_{x}, \dot{m}_{y}$ show the amplitude of polar wander that is equivalent to Peltier's values of $\left(\dot{C}_{21}, \dot{S}_{21}\right)$ would be $5.4{\mathrm{deg} \mathrm{Myr}^{-1}}^{-1}$. In contrast, the predicted polar wander speeds shown in Figures $1 \mathrm{~b}$ and 8 of Peltier and Luthcke [2009] are on the order of $1 \mathrm{deg} \mathrm{Myr}^{-1}$ or less, i.e., 5-6 times smaller than the values that are consistent with the $\left(\dot{C}_{21}, \dot{S}_{21}\right)$ results. The published $\left(\dot{C}_{21}, \dot{S}_{21}\right)$ predictions and the published polar wander predictions cannot both be correct. We do not know the reason for this discrepancy, but we suspect that a $\leq 1 \mathrm{deg} \mathrm{Myr}^{-1}$ polar wander speed is probably correct for this model. A value of $1 \mathrm{deg} \mathrm{Myr}^{-1}$ is close to the observed value, and Peltier and Luthcke [2009] explain that one of the successes of
Peltier's GIA model is that it is able to reproduce the observed polar wander rate. It should be noted that the multiplicative factor in equation (7) depends on the numerical value of $A /(C-A)$. A GIA model that computes all such quantities so that they are consistent with the model's input density profile could be using an effective value of $A /(C-A)$ that differs somewhat from the observed value. But unless the input density profile is hugely different from the real Earth's, the effect on $A /(C-A)$ would not be large (we find that for reasonable density profiles, a spread of $\pm 10 \%$ is conceivable), and could not explain the discrepancy noted above.

[26] Suppose we assume that the $\left(\dot{C}_{21}, \dot{S}_{21}\right)$ values in Peltier's model are incorrect and that instead they should be consistent with Argus and Gross' [2004] observed polar wander rates of $\left(\dot{m}_{x}, \dot{m}_{y}\right)=(0.4,-1.0) \mathrm{deg} \mathrm{Myr}^{-1}$. (We suspect they should be even smaller than this, based on the modeled values shown in Figure 8 of Peltier and Luthcke [2009].) That would imply that Peltier's $\left(\dot{C}_{21}, \dot{S}_{21}\right)$ values should, instead, be

$$
\left(\begin{array}{l}
\dot{C}_{21} \\
\dot{S}_{21}
\end{array}\right)=\left(\begin{array}{c}
-0.6 \times 10^{-11} \\
1.4 \times 10^{-11}
\end{array}\right) \quad \mathrm{yr}^{-1}
$$

Using Peltier's GIA geoid rates, but replacing the model values of $\left(\dot{C}_{21}, \dot{S}_{21}\right)$ with the numbers given in (9) (and removing the global mean and degree 1 terms), gives a GRACE ocean mass correction of $-1.22 \mathrm{~mm} \mathrm{yr}^{-1}$, which now agrees with the Paulson et al. correction $(-1.27)$ to better than $5 \%$.

[27] The resulting map of the GRACE-minus-Peltier results, computed using the values given in (9), is shown in Figure 1e. This map now does not include the four anomalous lobes evident in Figures 1c and 1d and, in fact, looks quite similar to the GRACE-minus-Paulson et al. map shown in Figure 1b.

\section{Conclusions}

[28] Geoid rates from two GIA models [Peltier, 2004; Paulson et al., 2007] have been compared with each other and with geoid rates from GRACE for the period August 2002 to November 2009. Although both models are based on the same ice loading history and use similar viscosity profiles, they lead to substantially different corrections for GRACE ocean mass estimates. There appear to be two reasons for this difference.

[29] One is that the Peltier geoid rate includes a nonzero global bias that increases the GRACE ocean mass correction by $0.4 \mathrm{~mm} \mathrm{yr}^{-1}$. This bias, which is needed when correcting sea surface height observations for the effects of GIA, should not be included when removing GIA contributions from GRACE gravity observations. It does not represent a real change in the Earth's gravitational potential, because it violates conservation of mass: it implies the GIA process is causing the total mass of the Earth + ice + oceans to decrease. When we remove the global bias and the degree 1 terms from Peltier's model (the degree one terms are zero in the center-of-mass reference frame used by GRACE; though Peltier's values are small enough to have little impact on the GRACE correction), and use an ocean kernel that minimizes leakage from hydrology and present-day ice 
mass changes, the ocean mass correction rate decreases significantly, but is still $28 \%$ (i.e., $0.34 \mathrm{~mm} \mathrm{yr}^{-1}$ ) larger than the value predicted by Paulson et al. [2007].

[30] The remaining difference comes almost entirely from the model predictions of the $\left(\dot{C}_{21}, \dot{S}_{21}\right)$ coefficients. The Peltier [2004, 2009] model prefers causes large geoid trends in the ocean that are not observed by GRACE. Peltier and Luthcke [2009] argue that these trends could conceivably be due to rotation-induced deformation caused by contemporary changes in land-based ice. But when we adjust the results to account for that deformation, the large ocean trends still remain. In order for such a large signal in the ocean to be masked by ocean dynamics, the ocean bottom pressure changes would have to be significantly larger than anything that has been observed or modeled. For example, over the GRACE observational period, the largest trend in ocean bottom pressure occurs in the far North Pacific and has been verified by steric-corrected altimetry even though it does not appear in an ocean model [Chambers and Willis, 2008]. Even though the OBP trend is of order $1 \mathrm{~cm} \mathrm{yr}^{-1}$ in sea level change over much of the subpolar gyre, it is hardly noticeable in terms of geoid rates (Figure 1a) and is far smaller than the geoid rates implied by the Peltier model (Figure 1c). The model of Paulson et al. [2007], on the other hand, predicts significantly smaller $\left(\dot{C}_{21}, \dot{S}_{21}\right)$ values and does not introduce such large geoid changes in the ocean when removed from GRACE. When we use the newer GDR-C Jason-1 data that corrects a bias at the end of the record to compute GMSL, we find closure of the sea level budget after 2005 at the $0.2 \mathrm{~mm} \mathrm{yr}^{-1}$ level, but only if we utilize the Paulson et al. [2007] GIA correction.

[31] We do not know the reason for the large differences between the $\left(\dot{C}_{21}, \dot{S}_{21}\right)$ values for the two models. We find, though, that Peltier's [2004] predicted $\left(\dot{C}_{21}, \dot{S}_{21}\right)$ values are inconsistent with his predicted polar wander speeds; his predicted $\left(\dot{C}_{21}, \dot{S}_{21}\right)$ rates appear to be 5-6 times too large. When his $\left(\dot{C}_{21}, \dot{S}_{21}\right)$ rates are reduced to match his predicted polar wander speeds (the latter are close to the observed values), the anomalous features in the GRACE-minusPeltier maps disappear, and the resulting GRACE mass correction agrees with the Paulson et al. correction to better than $5 \%$.

[32] On the basis of this cumulative evidence, we conclude that the Paulson et al. [2007] GIA model as distributed is more consistent with the GRACE observations. However, even this model should be used with caution. There are still unknown uncertainties in both the mantle viscosity structure and the ice loading history needed for GIA models. Only one global model (ICE-5G [Peltier, 2004]) is readily available, so most GIA models are biased toward this.

[33] On the basis of this, we cannot propose a single value for a correction to the GRACE data. Users should apply a model based on their specific averaging kernel, as this study has demonstrated that the correction is highly dependent on the ocean kernel used in the calculation. Ocean kernels computed by different authors can introduce differences of up to $0.3 \mathrm{~mm} \mathrm{yr}^{-1}$ of equivalent sea level change. In addition, the uncertainies associated with the mantle viscosity and ice loading history on GIA models have not been fully quantified. Although we have been able to explain the major differences between ocean mass corrections given by two GIA models, the possibility of common errors in GIA models is still probably the largest source of uncertainty in computing ocean mass trends from GRACE observations.

\section{Appendix A}

[34] Any process that involves the redistribution of mass within the Earth or at its surface can cause changes in the Earth's inertia tensor and in its rotation vector. If the time scale of that process is several years or longer, then there is a simple relation between changes in the products of inertia and changes in the pole position. We review that relation in this appendix.

[35] Consider a process that changes the Earth's mass distribution. For the purposes of this paper, it could be GIA, or it could be a long-term trend in contemporary land-based ice mass. Define the complex variables $\bar{m}(t)=m_{x}(t)+i m_{y}(t)$ and $\bar{I}(t)=I_{x z}(t)+i I_{y z}(t)$ to represent time variations in the pole position $\left(m_{x}\right.$ and $m_{y}$ are the components of the rotation axis in the mean equatorial plane) and in the products of inertia, respectively. Here $\bar{I}$ includes all contributions: the direct effects of any present-day mass loads, the effects of elastic or viscoelastic solid Earth deformation caused by present-day or past mass loads, and the effects of deformation induced by motion of the rotation axis. The Liouville equation for polar motion, derived from the equation for conservation of the Earth's angular momentum, is (e.g., equation (6.1.7) of Munk and MacDonald [1975]),

$$
\frac{i \mathrm{~d} \bar{m} / \mathrm{d} t}{\Omega\left(\frac{C-A}{A}\right)}+\bar{m}=\frac{1}{C-A}\left(\bar{I}-\frac{i \mathrm{~d} \bar{I} / \mathrm{d} t}{\Omega}\right),
$$

where $C$ and $A$ are the Earth's polar and equatorial moments of inertia and $\Omega$ is the Earth's mean rotation rate. To obtain this form for (A1), we used the fact that there is no external torque on the Earth and that the rotation parameter $\bar{m}(t)$ represents the Earth's mean rotation vector, so that the relative angular momentum vanishes by definition. For periods much longer than 1 day, $i \mathrm{~d} \bar{I}^{\mathrm{TOT}} / \mathrm{d} t \ll \Omega \bar{I}^{\mathrm{TOT}}$ (because $\Omega=$ $1 \mathrm{cycle} / \mathrm{d})$. And for periods much longer than 10 months, $i \mathrm{~d} \bar{m} / \mathrm{d} t \ll[\Omega(C-A) / A] \bar{m}$ (because $\Omega(C-A) / A=1$ cycle $/$ 10 months). In this case, (A1) reduces to

$$
\bar{m}(t)=\frac{\bar{I}(t)}{C-A} .
$$

Letting $\dot{\bar{m}}$ and $\dot{\bar{I}}$ represent the long-term trends in $\bar{m}$ and $\bar{I}$, (A2) implies

$$
\dot{\bar{m}}=\frac{\dot{\bar{I}}}{C-A} .
$$

[36] The relation (A2) between long-term variations can also be derived directly from the Liouville equation without removing the time-derivative terms in (A1) by assuming the mass distribution is described by a slowly varying term and integrating the resulting Liouville equation over time. This approach is described by Lambeck [1980] (see Lambeck's equation (4.3.8)). The solution for $\bar{m}(t)$ in this case consists of a slowly varying term plus an excited Chandler Wobble: the effect of the $i \mathrm{~d} \bar{m} / \mathrm{d} t$ term in (A1) is to cause that Chandler Wobble. The slowly varying term in the result for $\bar{m}(t)$ is related to the slowly varying term in the product of inertia, as described by (A2). 
[37] The result (A3), which is used in the text to derive (4) and (6), shows that for long period excitations the secular drift of the pole is directly proportional to the trend in the products of inertia. The result is routinely used in GIA models. Consider, for example, the polar motion equations described by Peltier and Luthcke [2009]. Combining equations (11a) and (11b) of Peltier and Luthcke gives

$$
\bar{m}(s)-\frac{k^{\mathrm{T}}(s)}{k_{\mathrm{f}}} \bar{m}(s)=\frac{\Omega}{A \sigma}\left(1+k^{\mathrm{L}}(s)\right) \bar{I}^{\mathrm{R}}(s),
$$

where $s$ denotes the Laplace transform variable, $k^{\mathrm{T}}(s)$ and $k^{\mathrm{L}}(s)$ are the degree 2 body tide and load tide Love numbers, $k_{\mathrm{f}}$ is the fluid Love number, and $\bar{I}^{\mathrm{R}}$ represents the direct effect of the mass loading. Transforming from the Laplace transform domain to the time domain, gives

$$
\bar{m}(t)-\frac{k^{\mathrm{T}}(s)}{k_{\mathrm{f}}} * \bar{m}(t)=\frac{\Omega}{A \sigma}\left(1+k^{\mathrm{L}}(t)\right) * \bar{I}^{\mathrm{R}}(t),
$$

where the asterisk denotes convolution in time. From equations (16) and (17) of Peltier [2007],

$$
\left(1+k^{\mathrm{L}}(t)\right) * \bar{I}^{\mathrm{R}}(t)=\bar{I}^{\mathrm{GIA}}(t)
$$

( $\bar{I}^{\mathrm{GIA}}$ is equivalent to $\bar{I}^{\mathrm{L}}$ described above in (1)) and

$$
\frac{k^{\mathrm{T}}(s)}{k_{\mathrm{f}}} * \bar{m}(t)=\frac{1}{(C-A)} \bar{I}^{\mathrm{ROT}}(t) .
$$

So since $\frac{\Omega}{A \sigma}=\frac{1}{(C-A)}$ [see Peltier, 2007, equation (19c)], (A4) reduces to

$$
\bar{m}(t)=\frac{1}{C-A}\left(\bar{I}^{\mathrm{ROT}}(t)+\bar{I}^{\mathrm{GIA}}(t)\right)=\frac{1}{C-A} \bar{I}(t) .
$$

Taking the time derivative of (A5) gives (A3) above.

[38] Acknowledgments. The GRACE data are furnished by the GRACE Science Data System and are available at the NASA Physical Oceanography Distributed Active Archive Center (PO.DAAC) at Jet Propulsion Laboratory, Pasadena, California. We are grateful to W. R. Peltier for providing his predicted GIA geoid rates, to Geruo A and Shijie Zhong for help with the Paulson et al. model, to J. Willis for providing steric data from the Argo profilers, and to Riccardo Riva and three anonymous reviewers/editors for their comments on the text. This research was carried out under a grant from the NASA Interdisciplinary Science Team and the NERC Oceans 2025 program. Work at the University of Colorado was partially supported by contracts 1259025 and 1390432 from the Jet Propulsion Laboratory.

\section{References}

Agnew, D. C., and W. E. Farrell (1978), Self-consistent equilibrium ocean tides, Geophys. J. R. Astron. Soc., 55, 171-181.

Argus, D. F., and R. S. Gross (2004), An estimate of motion between the spin axis and the hot spots over the past century, Geophys. Res. Lett., 31, L06614, doi:10.1029/2004GL019657.

Bettadpur, S. (2007), Level-2 Gravity Field Product User Handbook, GRACE 327-734, CSR Publ. GR-03-01, Rev 2.3, 19 pp., Univ. of Texas at Austin, Austin, Tex.

Cazenave, A., K. Dominh, S. Guienhut, E. Berthier, W. Llovel, G. Ramillien, M. Ablain, and G. Larnicol (2009), Sea level budget over 2003-2008: A reevaluation from GRACE space gravimetry, satellite altimetry and Argo, Global Planet. Change, 65(1-2), 83-88, doi:10.1016/j.gloplacha.2008. 10.004 .

Chambers, D. P. (2006), Evaluation of new GRACE time-variable gravity data over the ocean, Geophys. Res. Lett., 33, L17603, doi:10.1029/ 2006GL027296.
Chambers, D. P. (2009), Calculating trends from GRACE in the presence of large changes in continental ice storage and ocean mass, Geophys. J. Int., 176, 415-419, doi:10.1111/j.1365-246X.2008.04012.x.

Chambers, D. P., and J. K. Willis (2008), Analysis of large-scale ocean bottom pressure variability in the North Pacific, J. Geophys. Res., 113, C11003, doi:10.1029/2008JC004930.

Chao, B. F., and R. S. Gross (1987), Changes in the Earth's rotation and lowdegree gravitational field induced by earthquakes, Geophys. J. R. Astron. Soc., 91, 569-596.

Cheng, M., and B. D. Tapley (2004), Variations in the Earth's oblateness during the past 28 years, J. Geophys. Res., 109, B09402, doi:10.1029/ 2004JB003028.

Groten, E. (2004), Fundamental parameters and current (2004) best estimates of the parameters of common relative to astronomy, geodesy, and geodynamics, J. Geod., 77, 724-731.

Ivins, E. R., and D. Wolf (2008), Glacial isostatic adjustment: New developments from advanced observing systems and modeling, J. Geod., 46, 69-77, doi:10.1016/j.jog.2008.06.002.

Lambeck, K. (1980), The Earth's Variable Rotation: Geophysical Causes and Consequences, 450 pp., Cambridge Univ. Press, New York.

Leuliette, E. W., and L. Miller (2009), Closing the sea level rise budget with altimetry, Argo, and GRACE, Geophys. Res. Lett., 36, L04608, doi:10.1029/2008GL036010.

Lombard, A., D. Garcia, G. Ramillien, A. Cazenave, R. Biancale, J. M. Lemoine, F. Flechtner, R. Schmidt, and M. Ishii (2007), Estimation of steric sea level variations from combined GRACE and Jason-1 data, Earth Planet. Sci. Lett., 254, 194-202, doi:10.1016/j.epsl.2006.11.035.

Milne, G. A., J. L. Davis, and J. X. Mitrovica (2001), Space-geodetic constraints on glacial isostatic adjustment in Fennoscandia, Science, 291, 2381-2385, doi:10.1126/science.1057022.

Mitrovica, J. X., J. Wahr, I. Matsuyama, and A. Paulson (2005), The rotational stability of an ice-age Earth, Geophys. J. Int., 161, 491-506, doi:10.1111/j.1365-246X.2005.02609.x.

Munk, W. H., and G. J. H. MacDonald (1975), The Rotation of the Earth: A Geophysical Discussion, pp. 323, Cambridge Univ. Press, New York.

Paulson, A., S. Zhong, and J. Wahr (2007), Inference of mantle viscosity from GRACE and relative sea level data, Geophys. J. Int., 171, doi:10.1111/j.1365-246X.2007.03556.x.

Peltier, W. R. (2004), Global glacial isostasy and the surface of the ice-age Earth: The ICE-5G (VM2) model and GRACE, Annu. Rev. Earth Planet. Sci., 32, 111-149, doi:10.1146/annurev.earth.32.082503.144359.

Peltier, W. R. (2007), History of Earth rotation, in Treatise on Geophysics, vol. 9, Evolution of the Earth, edited by D. Stevenson, pp. 243-293, Elsevier, Oxford, UK

Peltier, W. R. (2009), Closure of the budget of global sea level rise over the GRACE era: The importance and magnitudes of the required corrections for global glacial isostatic adjustment, Quat. Sci. Rev., 28, 1658-1674, doi:10.1016/j.quascirev.2009.04.004.

Peltier, W. R., and S. B. Luthcke (2009), On the origins of Earth rotation anomalies: New insights on the basis of both "paleogeodetic" data and Gravity Recovery and Climate Experiment (GRACE) data, J. Geophys. Res., 114, B11405, doi:10.1029/2009JB006352.

Rodell, M., et al. (2004), The global land data assimilation system, Bull. Am. Meteorol. Soc., 85(3), 381-394.

Swenson, S. C., and J. Wahr (2006), Post-processing removal of correlated errors in GRACE data, Geophys. Res. Lett., 33, L08402, doi:10.1029/ 2005GL025285.

Smith, M. L., and F. A. Dahlen (1981), The period and Q of the Chandler wobble, Geophys. J. R. Astron. Soc., 64, 223-281.

Wahr, J., M. Molenaar, and F. Bryan (1998), Time-variability of the Earth's gravity field: Hydrological and oceanic effects and their possible detection using GRACE, J. Geophys. Res., 103(B12), 32,205-30,229, doi:10.1029/98JB02844.

Willis, J. K., D. P. Chambers, and R. S. Nerem (2008), Assessing the globally averaged sea level budget on seasonal to interannual time scales, J. Geophys. Res., 113, C06015, doi:10.1029/2007JC004517.

Wu, X., M. B. Heflin, E. R. Ivins, and I. Fukumori (2006), Seasonal and interannual global surface mass variations from geodetic data combination, J. Geophys. Res., 111, B09401, doi:10.1029/2005JB004100.

D. P. Chambers, College of Marine Science, University of South Florida, St. Petersburg, FL 33701, USA. (dchambers@marine.usf.edu)

R. S. Nerem, CIRES, University of Colorado at Boulder, Boulder, CO 80309-0390, USA.

M. E. Tamisiea, Proudman Oceanographic Laboratory, Liverpool, L3 5DA, UK.

J. Wahr, Department of Physics, University of Colorado at Boulder, Boulder, CO 80309-0429, USA. 